\title{
Nonlinear dynamic analysis of long-span cable-stayed bridges with train-bridge and cable coupling
}

\author{
Zhihui Zhu ${ }^{1} \cdot$ Lidong Wang $^{1} \cdot$ Michael T. Davidson ${ }^{2} \cdot$ Issam E. Harik ${ }^{3} \cdot$ Anand Patil $^{4}$
}

Received: 31 August 2018 / Accepted: 14 May 2019 / Published online: 24 May 2019

(c) The Author(s) 2019

\begin{abstract}
Span lengths of newly constructed cable-stayed railway bridges continue to show increases relative to those of older bridges. Accompanying such increases is the importance of ensuring that vibrations of long-span cable-stayed bridges satisfy both safety and serviceability requirements, particularly for bridges that support train passages. In contrast to modern design of bridges that support roadway vehicles, current methods for analyzing cable-stayed railway bridges do not yet typically account for coupling effects that may occur between cables and the surrounding bridge structure during train passages. This paper presents a computational framework for the nonlinear dynamic analysis of railway bridges based on a coupled train-bridge analytical model and investigates the significance of accounting for cable-related coupling effects. A case study is then carried out, where coupled dynamic responses of cables, towers, and girders of an in-service railway bridge are computed and compared to those obtained using an uncoupled approach. These comparisons demonstrate the merits of accounting for coupling phenomena when computing dynamic characteristics of cable-stayed railway bridges and highlight benefits of the coupled analysis approach in bridge design applications.
\end{abstract}

Keywords Cable-stayed railway bridges · Long-span bridges · Geometric nonlinearity · Transient dynamic analysis . Coupled vibration analysis

Anand Patil

apatil@ce.ufl.edu

Zhihui Zhu

zzhh0703@csu.edu.cn

Lidong Wang

wangld6730@163.com

Michael T. Davidson

michael@ce.ufl.edu

Issam E. Harik

harik@uky.edu

1 School of Civil Engineering, Central South University, Changsha 410075, Hunan Province, China

2 Bridge Software Institute, Engineering School of Sustainable Infrastructure and Environment, University of Florida, Gainesville, FL 32605-0281, USA

3 Department of Civil Engineering, University of Kentucky, Lexington, KY 40506-0281, USA

4 Engineering School of Sustainable Infrastructure and Environment, University of Florida, Gainesville, FL 32605-0281, USA

\section{Introduction}

Considerations for the vibrations of long-span cable-stayed bridges that are produced during train passages are increasingly recognized as important components of modern design practice. For example, most of the long-span bridges constructed after the year 2000 have been evaluated through vehicle-bridge coupled vibration analysis (Zhai et al. 2013). The increased importance attributed to train-induced vibrations has been prompted by increases in constructed span lengths, train passage speeds, and train axle loads.

Characterization of dynamic behaviors that arise during train passages across long-span cable-stayed bridges is essential to upholding design constraints for safety and economy. Accordingly, many previous analytical studies have been carried out to quantify dynamic responses of cablestayed bridges to vehicular loads. The effects of traffic, random track irregularities (Au et al. 2001a, b), vehicle velocity, girder depth, cable arrangements (Zaman et al. 1996) have all been previously investigated. Further, numerous mechanical models and specialized (numerical) elements have been developed to describe principle components of 
train and cable-stayed bridge systems. Relevant examples include networks of discrete spring-mass elements to represent trains (Yau and Yang 2004); specialized truss elements for bridge stay cables ( $\mathrm{Li}$ et al. 2015a); and nonlinear beam-column elements for bridge decks and pylons (Yau and Yang 2004).

The importance of accounting for local vibrations as contributors to global dynamic response of cable-stayed bridges has been consistently recognized in previous studies (AbdelGhaffar and Khalifa 1991; Warnitchai et al. 1995; Caetano et al. 2008; Zárate and Caicedo 2015). Even so, motions arising along cables are often neglected in design applications. Instead, stiffness contributions of cables to global structural behavior are typically taken into account by treating each cable as a "one element cable system" (OECS) with Ernst (1965) equivalent modulus (Caetano et al. 1996; Yau and Yang 2004; Bruno 2008). Consequently, the effects of cable vibrations on bridge deck and pylon responses (e.g., nonlinearities associated with beam-column effects; the initial equilibrium state; and large-displacement kinematics effects) are neglected (Cai and Aref 2014).

\section{Objectives}

The objectives of this study are to: (a) present a computational framework for calculating nonlinear dynamic responses of long-span cable-stayed bridges subjected to moving trains, where train-bridge coupled vibrationsincluding those of the cables-are taken into account; and (b) identify advantages of the proposed approach relative to the OECS model. In achieving these objectives, results obtained from use of the proposed framework and OECS model are compared as part of a case study of heavy-haul train passages along an in-service long-span cable-stayed bridge. Such comparisons demonstrate the merit of considering cable local vibrations in computing system response during high-speed rail passage events.

\section{Coupled analysis of train passages on cable-stayed bridges}

A computational framework is presented for conducting nonlinear dynamic analysis of coupled cable-stayed bridge response and combines several previously established FE formulations and analysis techniques. Organization of these computational tools (Fig. 1) extends the previously validated framework from Zhu et al. (2017). Further, the extended framework enables the current investigation into mechanisms of interaction between the "local" and "global" vibrations of coupled train-bridge-cable systems.

The computational framework begins (Fig. 1, upper left) with the formation of a train model; track-bridge (including cables) FE model; and analytical wheel-rail contact model, where each model component is discussed later. Track-bridge FE model components are utilized in static, and ultimately, transient dynamic analyses. Consequently, the need to determine a sufficient number of vibration modes for analysis is avoided, especially those modes related to inclusion of the track structure (Guo et al. 2012). Geometric nonlinearitiesincluding cable sagging, beam-column effects, and largedisplacement kinematics-are considered in the track-bridge FE model, along with accurate (yet efficient) representations of cables. Necessarily then, an updated Lagrangian formulation is employed, and the initial static equilibrium state of the track-bridge FE model is obtained prior to conducting time history analysis.

The computational approach validated in Zhu et al. (2017) is employed in coupling the analytical wheel-rail contact algorithm and bridge FE model, where train and wheel-rail contact model components were adopted from Chen and Zhai (2004). Furthermore, track random irregularities (vertical and lateral directions) are incorporated into both the analytical model and rail geometry in the FE model.

The aforementioned framework components are next assembled and initialized within an equation of motion for the coupled train-track-bridge (Fig. 1, left center). Subsequently, a nonlinear dynamic (time history) analysis is carried out. For each time step, the train motion (position) is considered relative to the track-bridge motion to establish wheel-rail interaction forces (Fig. 1, left center). Interaction forces are then used to compute the updated train position while an iterative tangent stiffness procedure is utilized ("Entry A" in Fig. 1) to converge upon an equilibrium state for the track-bridge system.

Upon reaching convergence of the tangent stiffness procedure ("Entry A"), positions of the track-bridge FE model nodes are updated (Fig. 1, left bottom). Mutual convergence of the train system and track-bridge system is then assessed. If mutual convergence is not achieved, then the wheel-rail interaction forces are updated (Fig. 1, left center) based on the train and rail-bridge FE model positions determined as part of the current iteration. An additional iteration is then carried out to update train and track-bridge motions. Otherwise, if convergence of the train position, wheel-rail interaction forces, and track-bridge FE nodal positions is achieved (Fig. 1, left bottom), the time step is incremented $(t=t+d t)$. The time stepping is continued until mutual system convergence is achieved for the final time step (Fig. 1, left bottom). Subsystems making up the computational framework (Fig. 1) are discussed immediately below. 


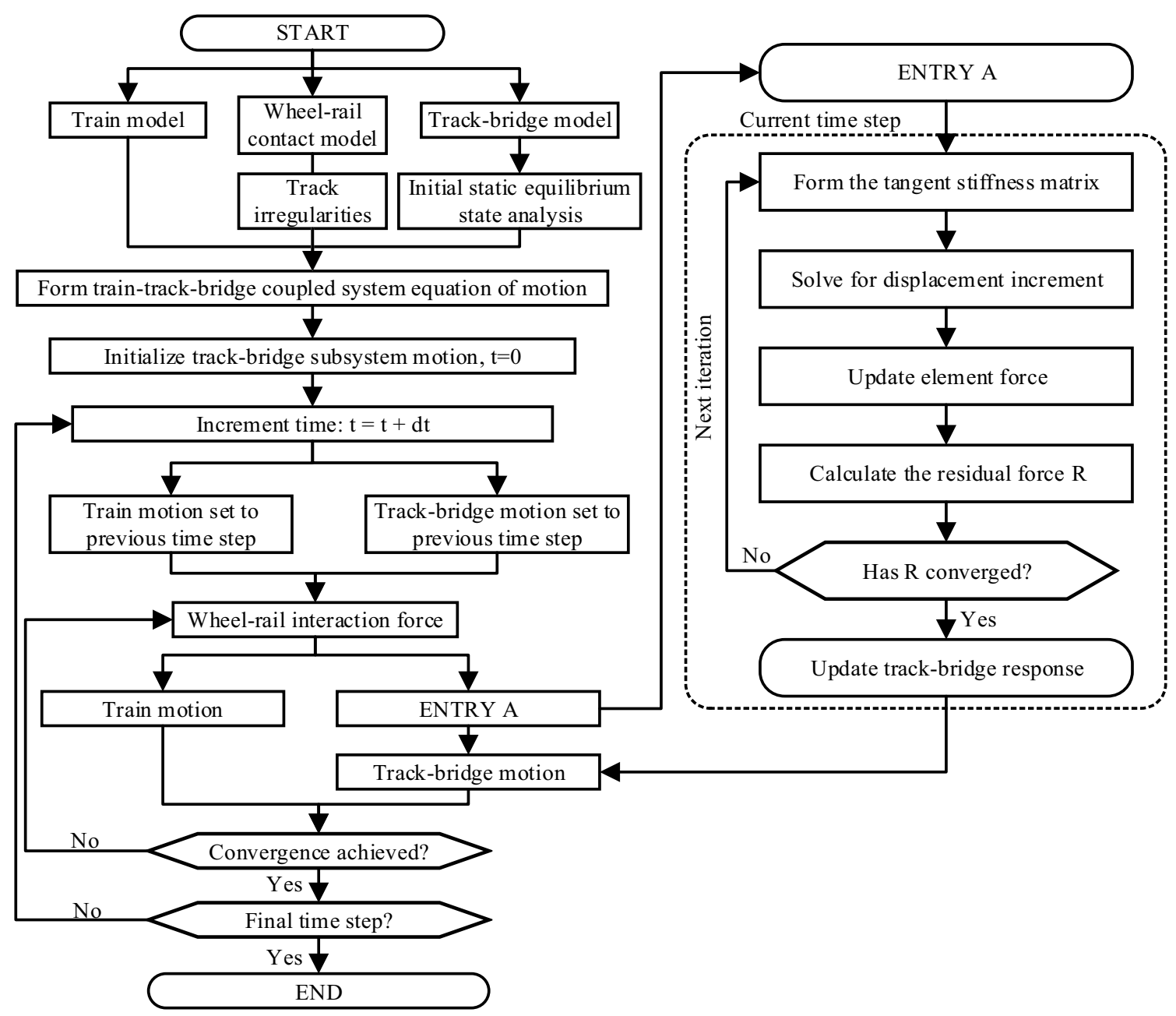

Fig. 1 Computational framework for coupled nonlinear dynamic analysis of cable-stayed bridges subjected to high-speed rail passages

\section{Modeling of train and bridge}

\section{Train}

Each vehicle of the train usually consists of one car body, four wheel sets, two bogies, primary suspension systems connecting the wheel sets to the bogies, and secondary suspension systems connecting the bogies to the car body. Vehicle models of varying complexity, from moving load models (Bruno 2008) to those consisting of dozens of degrees of freedom (DOFs), have been previously developed (Au et al. 2001a, b; Zhang et al. 2008; Li et al. 2015b). In this study, it is assumed that train passages occur at constant speed, and train longitudinal DOFs are ignored. Each car body and bogie possesses five DOFs: sway $(Y)$; rolling $(\theta)$; yawing $(\psi)$; floating $(Z)$; and pitching $(\varphi)$, which are sufficient to capture motions of the vehicle components (Chen and Zhai 2004).

Wheel-set DOFs are related to the wheel-rail interaction model adopted in this study. Namely, per (Chen and Zhai
2004), wheel-set motions are defined by four DOFs: sway $(Y)$; rolling $(\theta)$; yawing $(\psi)$; and floating $(Z)$. In total, every vehicle (car body, bogie, wheel sets) is modeled using 31 independent DOFs. The collective DOFs (motions) for $n$ vehicles are expressed as:

$M_{\mathrm{V}} \ddot{X}_{\mathrm{V}}+C_{\mathrm{V}} \dot{X}_{\mathrm{V}}+K_{\mathrm{V}} X_{\mathrm{V}}=F_{\mathrm{V}}$

where $M_{\mathrm{V}}, C_{\mathrm{V}}$, and $K_{\mathrm{V}}$ constitute vehicle mass, damping, and stiffness matrices, respectively; $X_{\mathrm{V}}, \dot{X}_{\mathrm{V}}$, and $\ddot{X}_{\mathrm{V}}$ are time-varying displacement, velocity, and accelerations; and $F_{\mathrm{V}}$ contains forces that develop at each DOF of the train subsystem.

\section{Bridge}

In the proposed framework (recall Fig. 1), spatial vibration responses of bridges are estimated using 3D FE models. Accordingly, the bridge equation of motion is:

$M_{\mathrm{B}} \ddot{X}_{\mathrm{B}}+C_{\mathrm{B}} \dot{X}_{\mathrm{B}}+K_{\mathrm{B}} X_{\mathrm{B}}=F_{\mathrm{B}}$ 
where $M_{\mathrm{B}}, C_{\mathrm{B}}$, and $K_{\mathrm{B}}$ are the (consistent) mass, damping, and stiffness matrices of the track-bridge subsystem. Note that a consistent mass matrix formulation is required to capture torsional moments that arise in non-cable portions of the FE model during train passages, where such moments may induce unreasonable angular accelerations if a lumped mass formulation were to be adopted (Stolarski et al. 2007). Displacement, velocity, and acceleration vectors are denoted as $X_{\mathrm{B}}, \dot{X}_{\mathrm{B}}$, and $\ddot{X}_{\mathrm{B}}$, respectively; and $F_{\mathrm{B}}$ is the external force vector of the track-bridge subsystem.

\section{Wheel-rail contact model and system equation of motion}

Several methods have been proposed in literature for modeling both normal and tangential contact forces (as well as creep phenomena) that arise at the wheel-rail interface during train passages (Li et al. 2015b; Zhai et al. 2009). The spatial wheel-rail contact model proposed by Zhai (Chen and Zhai 2004) is adopted in the current study, which involves use of the contact trace curve method. In particular, Hertzian (nonlinear elastic) contact theory is utilized in computing normal contact forces between the wheel and rail:

$N_{z}(t)= \begin{cases}{\left[\frac{1}{G} \delta Z_{N}(t)\right]^{3 / 2},} & \delta Z_{N}(t)>0 \\ 0, & \delta Z_{N}(t) \leq 0\end{cases}$

where $G$ is the Hertzian wheel-rail contact constant $\left(\mathrm{m} / \mathrm{N}^{2 / 3}\right) ; \delta Z_{N}(t)$ is the normal direction "overlap" at the wheel-rail contact point $(\mathrm{m})$.

As an additional facet of the Chen and Zhai (2004) contact model, wheel-rail creep forces are calculated per Kalker linear creep theory. Nonlinearities that may arise in creep forces are considered by applying Shen-Hedrick-Elkins theory (Zhai et al. 1996). As a result, tangential wheel-rail contact forces can be expressed as:

$F_{x}=-\varepsilon \cdot f_{11} \xi_{x}$

$F_{y}=-\varepsilon \cdot f_{22} \xi_{y}-\varepsilon \cdot f_{23} \xi_{s p}$

$M_{z}=\varepsilon \cdot f_{23} \xi_{y}-\varepsilon \cdot f_{33} \xi_{s p}$

where $F_{x}$ and $F_{y}$ are, respectively, the longitudinal and lateral creep forces, with $f_{11}$ (longitudinal) and $f_{22}$ (lateral) creep factors; $M_{z}$ is the rolling creep moment, with $f_{23}$ as the rotational/lateral displacement creep factor and $f_{33}$ as the rolling creep factor; $\xi$ is the relative velocity difference between the wheel surface and rail surface. Subscripts $x, y$, and $s p$ indicate longitudinal, lateral, and rolling directions, respectively; and $\varepsilon$ is a correcting factor.

\section{Coupling of subsystem equations of motion}

The train subsystem equation of motion, Eq. (1), and track-bridge subsystem equation of motion, Eq. (2), are coupled by the interacting force vectors $F_{\mathrm{V}}$ and $F_{\mathrm{B}}$ [i.e., the righthand sides of Eqs. (1) and (2), respectively]. Consequently, two force vectors depend on the relative displacement, velocity, and acceleration between wheels and rail at the contact points, Eqs. (3)-(6). The two subsystems (train and track-bridge) are separately integrated using the Newmark- $\beta$ method, and interface compatibility is achieved through iteration (Zhang et al. 2008).

\section{Modeling the cables}

In the current study, the effects of utilizing more sophisticated modeling techniques for cables (relative to the OECS approach, Caetano et al. 1996) are investigated. The approach presented herein builds upon the "Multiple Element Cable System" (MECS) approach proposed by Caetano et al. (1996). Most importantly, kinematic nonlinearities such as cable sag are considered, which directly affect cable tension levels, and (in turn) influence global behaviors for progressively larger displacements.

Three modeling approaches that can —at varying levelsaccount for cable sagging are: (1) modified modulus method; (2) elastic catenary cable elements method; and (3) multipleshort truss elements method (Zárate and Caicedo 2015). The modified modulus method, which reproduces only bridge deck motions, neglects local cable transversal motion. The elastic catenary cable elements method and the multiple-short truss elements method converge toward identical responses as cable members are discretized into increasing numbers of straight truss elements (Warnitchai et al. 1995). However, the multipleshort truss elements method is more computationally feasible, especially when the cables are re-tensioned during construction, which often occurs in long-span cable-stayed bridges (Jie et al. 2015). Therefore, the multiple-short truss elements method is chosen herein to simulate both cable sag effects and cable local vibrations.

\section{Cable element stiffness and mass formulations}

In the local coordinate system of each two-node cable element, the original length of the element is $L_{0}$; the initial tension force is $P_{0}$; and the displacements in three directions $\left(x^{*}, y^{*}, z^{*}\right)$ are $\left(u_{i}, v_{i}, w_{i}\right)$ in node $i$ and $\left(u_{j}, v_{j}, w_{j}\right)$ in node $j$. The equilibrium equation of the element is (Wu et al. 2006):

$\frac{P}{\beta}\left[\begin{array}{llllll}-\alpha & -w & \alpha & v & w & -v\end{array}\right]^{\mathrm{T}}=\{F\}^{e}$ 
where $\alpha=L_{0}+u ; \beta=L_{0}+e ;\{F\}^{e}=\{-R-S-T R S T\}$ is the load vector, applicable to both node $i$ and node $j ; \quad P=P_{0}+E_{c} A_{c} / L_{0} \times e$ is the basic force;

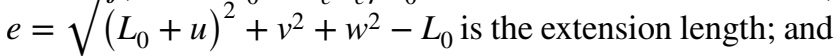
$u=u_{j}-u_{i}, v=v_{j}-v_{i}, w=w_{j}-w_{i}$ are the relative displacements between node $i$ and node $j . E_{c}$ and $A_{c}$ are Young's modulus and cross-sectional area, respectively.

By transforming partial basic forces into partial intermediate forces and partial intermediate displacements (Broughton and Ndumbaro 1995), the following equations are obtained:

$[K]^{e}\{\delta X\}^{e}=\{\delta F\}^{e}$

\section{Case study}

A long-span, cable-stayed bridge was modeled and analyzed using the proposed computational framework (recall Fig. 1). For this case study, the Dongting Lake Railway Cable-Stayed Bridge (DRCB) was selected as the structural configuration, discussed below, promotes comparisons of computed responses obtained from comparing OECS and extended MECS approaches to modeling cable stays. Also, the influence of lateral vibration on dynamic cable response was investigated.

$$
\begin{aligned}
{[K]^{e}=\frac{E_{c} A_{c}}{L_{0} \beta^{2}}\left[\begin{array}{cccccc}
\alpha^{2} & \alpha v & \alpha w & -\alpha^{2} & -\alpha v & -\alpha w \\
& v^{2} & v w & -\alpha v & -v^{2} & -v w \\
& w^{2} & -\alpha w & -v w & -w^{2} \\
& \alpha^{2} & \alpha v & \alpha w \\
\operatorname{sym} & & v^{2} & v w \\
& & & w^{2}
\end{array}\right] } \\
+\frac{P}{\beta^{3}}\left[\begin{array}{cccccc}
v^{2}+w^{2} & -\alpha v & -\alpha w & -v^{2}-w^{2} & \alpha v & \alpha w \\
& \alpha^{2}+w^{2} & -v w & \alpha v & -\alpha^{2}-w^{2} & v w \\
& & \alpha^{2}+v^{2} & \alpha w & v w & -\alpha^{2}-v^{2} \\
& & & v^{2}+w^{2} & -\alpha v & -\alpha w \\
& & & & \alpha^{2}+w^{2} & -v w \\
& & & \alpha^{2}+v^{2}
\end{array}\right]
\end{aligned}
$$

where $[K]^{e}$ is the element stiffness matrix in the local coordinate system; $\{\delta X\}^{e}=\left\{\delta u_{i} \delta v_{i} \delta w_{i} \delta u_{j} \delta v_{j} \delta w_{j}\right\}^{\mathrm{T}}$ is the incremental displacements for node $i$ and node $j$; and $\{\delta F\}^{e}$ is the corresponding incremental force.

A lumped mass matrix, $[M]^{e}$, is used for the cable elements:

$[M]^{e}=\frac{\rho_{c} A_{c} L_{0}}{2}[I]_{6 \times 6}$

where $\rho_{c}$ is mass density and $[I]$ is the unit matrix.

\section{Description of the DRCB}

The DRCB belongs to the West Inner Mongolia-Central China Railway and is the first triple-tower cable-stayed railway bridge in the world. The bridge overall length is $1288 \mathrm{~m}$ with the two main spans measured at $406 \mathrm{~m}$ and the two side spans at $98 \mathrm{~m}$ and $140 \mathrm{~m}$, respectively (Fig. 2). The full height of the towers is $157 \mathrm{~m}$, and the height of the towers above the deck is $113.5 \mathrm{~m}$. The superstructure consists of a box truss composite structure (Fig. 2), with members made of Q370qE grade steel.

The superstructure is also fitted with 156 stay cables (excluding stabilizing cables) forming a multiple doubleplane system that supports the bridge deck at 14-m intervals.

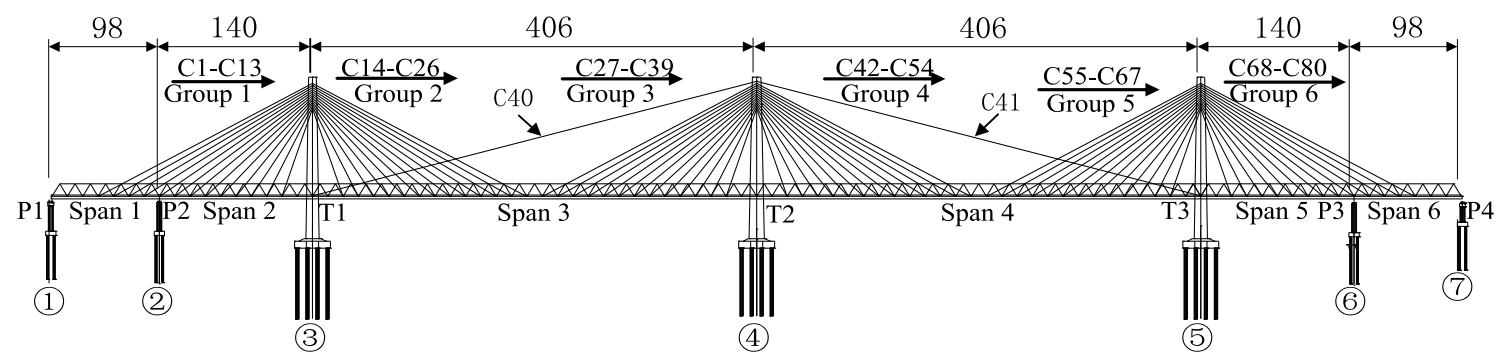

Fig. 2 Elevation schematic of Dongting Lake Railway Bridge (units: m) 
Because of the slender towers, eight longitudinal stabilizing cables with lengths of up to $465 \mathrm{~m}$ are used to connect the top of the central tower diagonally to the deck near the side towers. The stabilizing cables provide restraint for the central tower from traffic and vertical wind loading. The 164 bridge cables are divided into eight groups, ranging from 241 to 409 galvanized steel wires per cable, with wire diameters of $7 \mathrm{~mm}$ and tensile strengths of $1860 \mathrm{MPa}$. The cables are not grouted, but are covered with polyethylene tubes. The lengths of the shortest and longest cables are $77.5 \mathrm{~m}$ and $419 \mathrm{~m}$, respectively.

The superstructure is also fitted with 156 stay cables (excluding stabilizing cables) forming a multiple doubleplane system that supports the bridge deck at 14-m intervals. Because of the slender towers, eight longitudinal stabilizing cables with lengths of up to $465 \mathrm{~m}$ are used to connect the top of the central tower diagonally to the deck near the side towers. The stabilizing cables provide restraint for the central tower from traffic and vertical wind loading. The 164 bridge cables are divided into eight groups, ranging from 241 to 409 galvanized steel wires per cable, with wire diameters of $7 \mathrm{~mm}$ and tensile strengths of $1860 \mathrm{MPa}$. The cables are not grouted, but are covered with polyethylene tubes. The lengths of the shortest and longest cables are $77.5 \mathrm{~m}$ and $419 \mathrm{~m}$, respectively.

The bridge towers are Y-shaped, containing upper, middle, and lower tower columns and lower beams. Each tower consists of three cross sections at different heights. The concrete for these towers has a compressive strength of $50 \mathrm{MPa}$. The cables are numbered sequentially from the side to main span as shown in Fig. 2. The deck is $21 \mathrm{~m}$ in width and $2.34 \mathrm{~m}$ in height, including two longitudinal steel box girders along the deck edges with steel cross girders at $3.5 \mathrm{~m}$ intervals. Under the deck, longitudinal U-shaped stiffeners are used to strengthen sections and prevent buckling problems from the flat steel box girder.

\section{FE modeling}

The 3D, dynamic FE model of the DRCB (Fig. 3) was developed in ANSYS (2014). In this model, the towers and steel trusses were modeled using BEAM188 element and were based on the actual cross-sectional properties. Tower bases were fixed in all degrees of freedom. The geometric distances between cable ends and the cross-sectional centroids of the towers were represented by rigid bars.

An OECS model and a MECS model of the DRCB were developed (Fig. 3). For the MECS model, each longitudinal stabilizing cable was divided into 20 elements, and each main stay cable was modeled by 10 elements. Because the cables exhibited geometric nonlinearity due to sagging, there is no need to consider the equivalent modulus that allows for sagging. In comparison, a single-cable element was used to simulate a stay cable in the OECS model.

As a measure of modeling efficiency, an equivalent orthotropic material modeling method (Zhang et al. 2013) was used to model the orthotropic steel bridge deck details with multiple complicated stiffeners. This resulted in the same longitudinal and lateral stiffness in the unit width and shear stiffness in the shell plane when compared
Fig. 3 Finite element model of Dongting Lake Railway Bridge

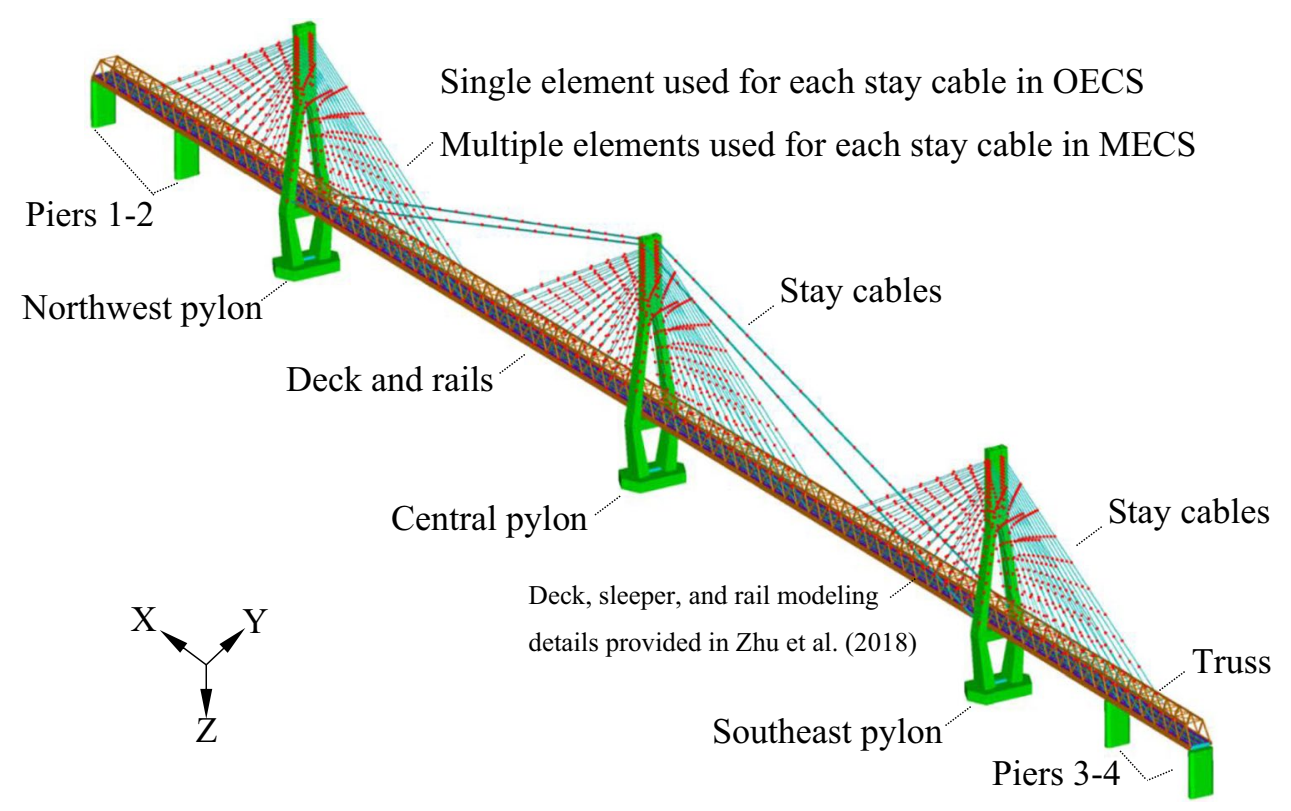


to the original configuration. In the "fish-bone" model (Asgari et al. 2013), the equivalent orthotropic shell element model has better structural details and was a better simulation for stiffness and mass distribution in the bridge deck sections.

A two-layer track model, presented in Zhu et al. (2018), was selected for modeling rails and sleepers. Of note, because these components have one dominant dimension, they were approximated by beam elements. The non-structural mass of the ballast bed was distributed uniformly across the girders. The rail pads and ballast are represented by distributed uniaxial tension-compression spring-dashpot elements acting in three directions. Estimating the coefficients of these representative springs and dampers, along with their validation, has been published previously (Jesus et al. 2014). All input data used to simulate the support of the ballast and rail pad are summarized in Table 1.

Table 1 Ballast and rail pad parameters

\begin{tabular}{lllcc}
\hline Parameter & Notation & Units & Rail pad & Ballast \\
\hline Density & $\rho_{b}$ & $\mathrm{~kg}$ & $\mathrm{~N} / \mathrm{A}$ & 1800 \\
Lateral stiffness & $k_{y}$ & $\mathrm{MN} / \mathrm{m}$ & 280 & 120 \\
Lateral damping & $c_{y}$ & $\mathrm{kN} \mathrm{s} / \mathrm{m}$ & 50 & 70 \\
Longitudinal stiffness & $k_{x}$ & $\mathrm{MN} / \mathrm{m}$ & 50 & 40 \\
Longitudinal damping & $c_{x}$ & $\mathrm{kN} \mathrm{s} / \mathrm{m}$ & 10 & 52 \\
Vertical stiffness & $k_{z}$ & $\mathrm{MN} / \mathrm{m}$ & 50 & 40 \\
Vertical damping & $c_{z}$ & $\mathrm{kN} \mathrm{s} / \mathrm{m}$ & 10 & 52 \\
\hline
\end{tabular}

Global modes and cable local modes

\section{Self-weight analysis}

The response of the cable-stayed bridge under self-weight loading provides important geometric data, base distributions of stresses, pretension forces in the cables, and it is a necessary precursor to investigating dynamic behaviors. The zero displacement method (Wang et al. 1993) was adopted to determine the initial shape of the DRCB. In this analysis, all nonlinearities (including cable sag, beam-column effects, and large displacements) were taken into account.

The initial shapes of the DRCB and the displacement of key points obtained by the OECS and MECS models are shown in Fig. 4. The overall deflection obtained by the MECS model is comparatively larger than that obtained by the OECS model. Furthermore, the multiple cable elements in the MECS model can effectively simulate the local deflection of each stay cable, whereas the OECS model is unable to capture motions along the cables. Cable stresses present in the OECS and MECS models under self-weight loading are presented in Fig. 5. Differences in prestress levels are within 5\% except for the stabilizing cable, which can have a maximum difference of $17 \%$. This indicates that using the OECS model to calculate prestress of super-long cable may lead to incorrect attribution of cable prestress levels.

\section{Modal study}

Building upon computed results from the deformed configuration under self-weight loading, modal analysis was performed to investigate dynamic behaviors of the DRCB

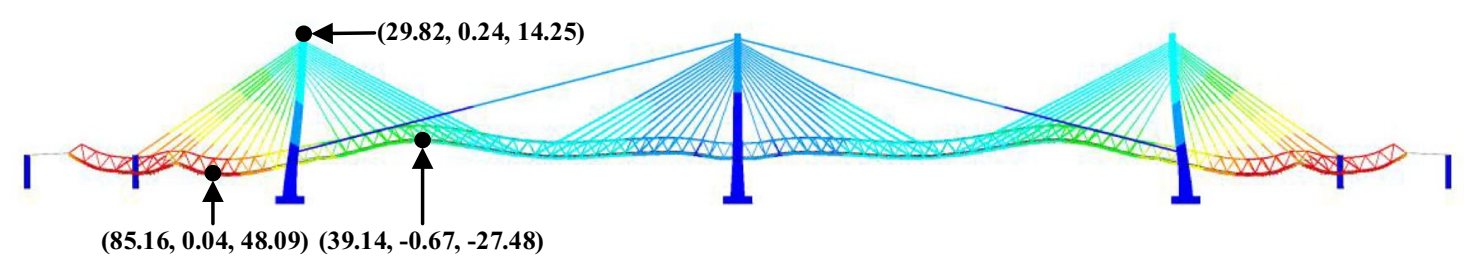

(a)

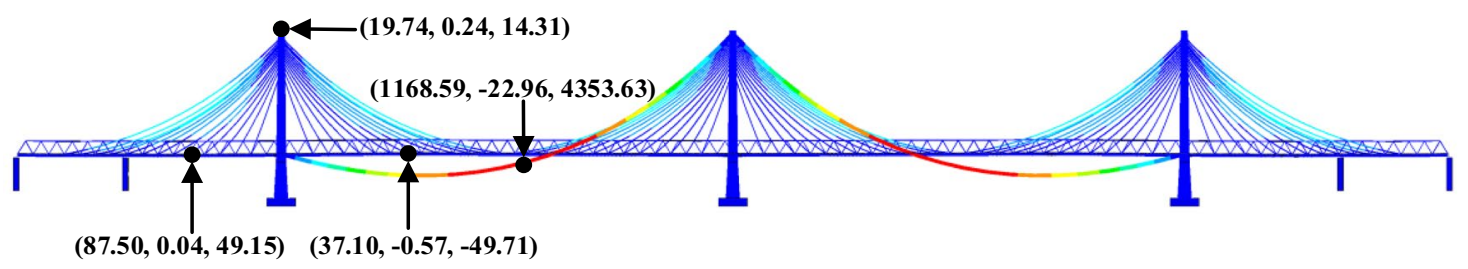

(b)

Fig. 4 Initial displacements ( $x, y, z$; in $\mathrm{mm})$ captured by $\mathbf{a}$ one element cable system; $\mathbf{b}$ multi-element cable system 
Fig. 5 Comparison of initial cable stresses due to self-weight loading

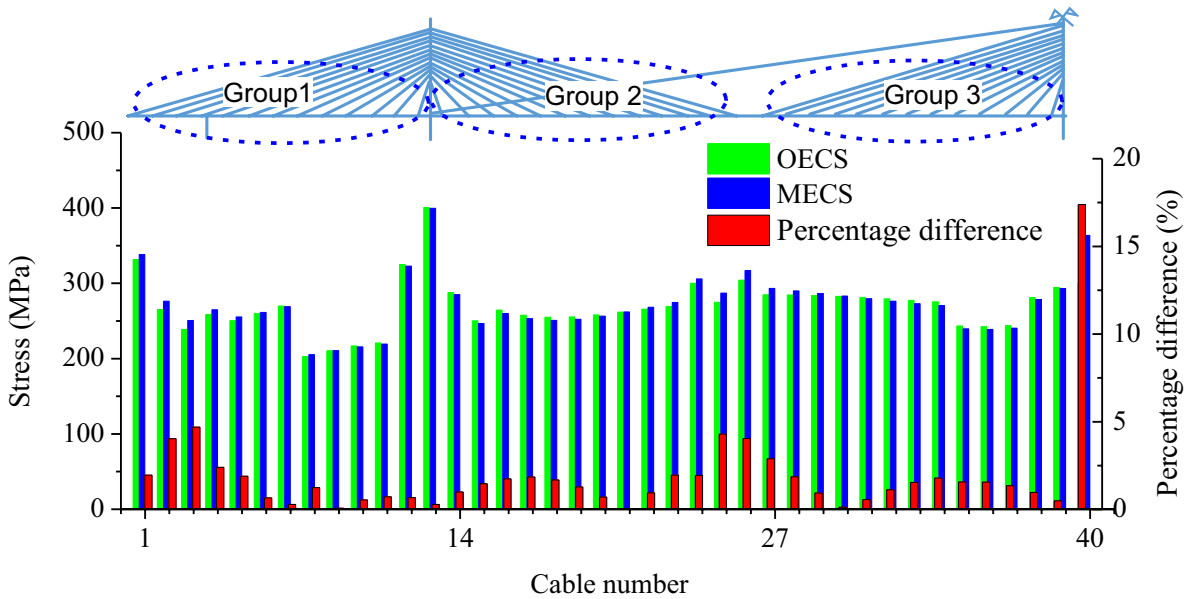

Table 2 Comparison of natural frequencies $(\mathrm{Hz})$ for the first 14 global modes

\begin{tabular}{|c|c|c|c|c|c|}
\hline \multicolumn{2}{|l|}{ OECS } & \multicolumn{2}{|l|}{ MECS } & \multirow{2}{*}{$\begin{array}{l}\text { Percent dif- } \\
\text { ference }(\%)\end{array}$} & \multirow[t]{2}{*}{ Description } \\
\hline Mode & Frequency $(\mathrm{Hz})$ & Mode & Frequency $(\mathrm{Hz})$ & & \\
\hline 1 & 0.273 & 5 & 0.274 & 0.29 & Asymmetrical lateral bending \\
\hline 2 & 0.320 & 10 & 0.320 & -0.03 & Symmetrical lateral bending \\
\hline 3 & 0.439 & 11 & 0.432 & -1.57 & Asymmetrical vertical bending \\
\hline 4 & 0.591 & 148 & 0.595 & 0.67 & Symmetrical vertical bending \\
\hline 5 & 0.606 & 153 & 0.601 & -0.72 & asymmetrical vertical bending \\
\hline 6 & 0.773 & 254 & 0.785 & 1.54 & Asymmetrical lateral bending \\
\hline 7 & 0.786 & 255 & 0.789 & 0.47 & Symmetrical lateral bending \\
\hline 8 & 0.829 & 272 & 0.839 & 1.25 & Tower lateral bending \\
\hline 9 & 0.845 & 273 & 0.842 & -0.33 & Asymmetrical lateral bending \\
\hline 10 & 0.894 & 294 & 0.894 & 0.01 & Asymmetrical vertical bending \\
\hline 11 & 0.895 & 306 & 0.901 & 0.73 & Symmetrical lateral bending \\
\hline 12 & 0.942 & 356 & 0.950 & 0.86 & Symmetrical vertical bending \\
\hline 13 & 1.069 & 429 & 1.076 & 0.73 & Symmetrical vertical bending \\
\hline 14 & 1.158 & 454 & 1.174 & 1.36 & Torsion \\
\hline
\end{tabular}

when modeled using the OECS and MECS approaches. Frequencies and mode shapes of the first 14 modes of the OECS model and first 1000 modes of the MECS model were found by the subspace method. As expected, the MECS model revealed global, local, and coupled modes of the bridge, whereas the OECS model only yielded the global modes.

Table 2 shows the first 14 natural frequencies of the global modes by the OECS and MECS model. The difference between the two models is no more than $1.5 \%$. This means that, in assessing the global dynamic behavior of the bridge, the effect of the model for cables is insignificant. Although the OECS model can reasonably simulate global motions, it fails to capture the mode shape of each individual stay cable or the interaction between the stay cables and the deck-tower system, since each stay cable is modeled with a single-cable element.

In contrast, the MECS model can effectively simulate the local and coupled motions. The natural frequencies of the first predominantly lateral, vertical, and torsional modes of the DRCB in the MECS model were $0.274 \mathrm{~Hz}, 0.432 \mathrm{~Hz}$, and $1.158 \mathrm{~Hz}$, respectively. Mode shapes with lateral (as opposed to vertical) vibration components are associated with relatively lower frequency levels. This phenomenon can be attributed to the relatively low span ratios of the DRCB and the relatively high vertical direction (as opposed to lateral direction) stiffness of the steel truss girder.

Among those modes captured by the MECS model, $85 \%$ were pure local cable vibration modes and coupled modes of cables, girder, and towers. The first eight predominantly global modes by the MECS model are shown in Fig. 6. The modal analysis revealed two features of the bridge. First, more than 1000 modes manifest at frequencies less than $1.5 \mathrm{~Hz}$. This indicates that the bridge has many closely spaced vibration modes with low frequencies. Some closely spaced modes manifest with similar modal shapes in the deck, but with differences in cable 


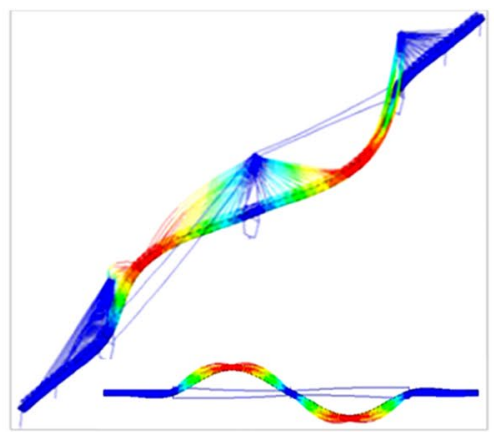

(a)

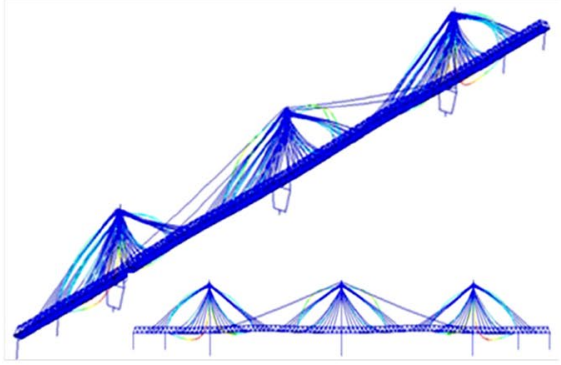

(d)

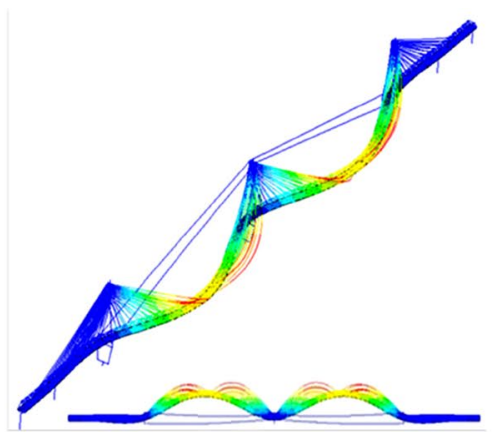

(b)

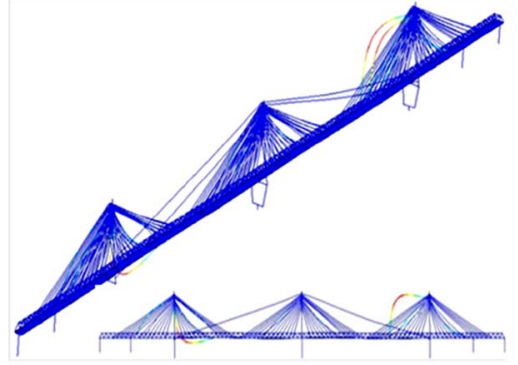

(e)

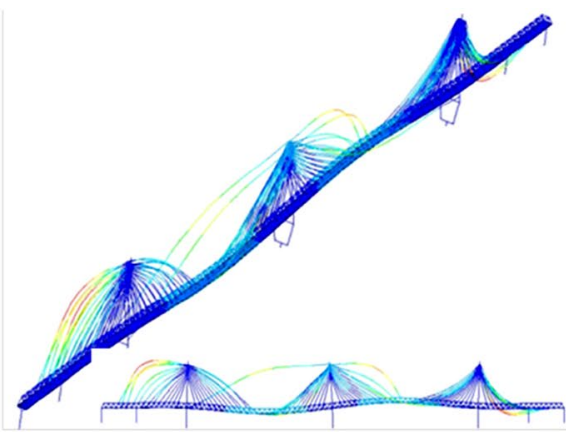

(c)

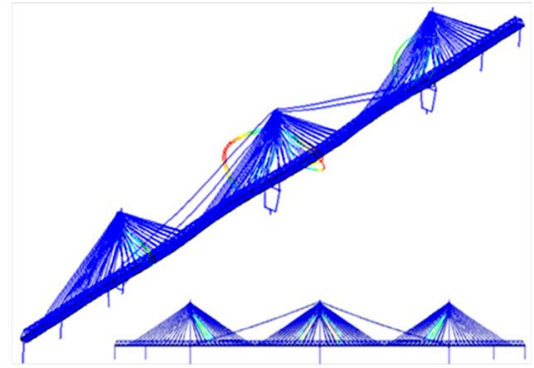

(f)

Fig. 6 Selected vibration modes of the cable-stayed bridge a 5th mode, $f=0.274 \mathrm{~Hz}$; b 10 th mode, $f=0.320 \mathrm{~Hz}$; $\mathbf{c} 11$ th mode, $f=0.432 \mathrm{~Hz}$; d 148th mode, $f=0.595 \mathrm{~Hz}$; e 153rd mode, $f=0.601 \mathrm{~Hz}$; 254 th mode, $f=0.785 \mathrm{~Hz}$

participation. The second feature of the bridge that was revealed by modal analysis was that modes based on the MECS model exhibited strong modal interaction between the deck, towers, and cables in some global modes. For example, Fig. 6 depicts the long cables vibrating with very large amplitude.

\section{Global vibration and local cable vibration}

To facilitate comparisons between the OECS and MECS approaches, the properties of local vibrations in the cables and global vibrations of the cable-stayed bridge were examined by using the train-bridge interaction model. Train-bridge coupled vibration analysis for the DRCB was conducted based on results of the self-weight and modal analyses. For all train-bridge analyses, track irregularities are assumed to be commensurate with a Class 5 track (per the U.S. Federal Railroad Administration).

The heavy-haul train used for train-bridge coupled vibration analysis consisted of one locomotive and up to 30 wagons (totaling $420 \mathrm{~m}$ in length), with passage speeds of $120 \mathrm{~km} / \mathrm{h}$. The locomotive was a SS4, which is approximately $2 \mathrm{~m}$ in width and $15.2 \mathrm{~m}$ in length with eight axles (each carrying a load of $230 \mathrm{kN}$ ). The main train type traversing the DRCB is the C80 freight wagon. Accordingly, wagons used in the analyses were of type C80, which is approximately $13 \mathrm{~m}$ in length and consisted of four axles with loads of up to $250 \mathrm{kN}$ per axle.

\section{Vibrations of the girders and towers}

Maximum vertical acceleration of the main girder reached 2.257 and $2.248 \mathrm{~m} / \mathrm{s}^{2}$, respectively, for the OECS and MECS models. Maximum lateral acceleration reached 0.737 and $0.743 \mathrm{~m} / \mathrm{s}^{2}$, respectively (OECS vs. MECS), which was far below the prescribed code limits (CMR 2005) for track stability, i.e., $3.5 \mathrm{~m} / \mathrm{s}^{2}$ (vertical) and $1.4 \mathrm{~m} / \mathrm{s}^{2}$ (lateral) for bridges with ballasted tracks. Regardless of modeling approach, these results support that the design requirements for DRCB track stability were satisfied.

Figure 7 shows maximum accelerations of points along pylon 2, as determined by the OECS and MECS approaches. It was observed that the maximum acceleration and displacement of the MECS model, especially components in the longitudinal direction, were greater than those of the OECS model. The percentage differences of maximum acceleration in the longitudinal direction at the top of pylon 2 were $15 \%$. These differences are due to the influence of MECS cable vibrations on girder-tower response, where such cable vibrations cannot be accounted for in the OECS model. 
Figure 8 shows MECS model deflection time histories for accelerations at the midpoints of span 1,2, and 3 on the bridge deck. Vertical displacement magnitudes are positively correlated with span length, while vertical accelerations are negatively correlated. This indicated that the greater the bridge mass, the smaller the acceleration of the mid-span.

According to the peak values shown in Fig. 8, the corresponding deflection-to-span ratios of span 1 to 3 are $1 / 4667 ; 1 / 4035$; and $1 / 1442$, respectively-further indicating the prominent vertical stiffness of the cable-stayed bridge. Impact factors of vertical displacement at the midpoint of span 1 to $3(0.0005,0.005$, and 0.0003 , respectively) indicated that deflections were mainly induced by the train axle load, and the effect of track irregularities is insignificant.

\section{Vibrations of the cables}

Figure 9 gives the maximum response of the cable midpoint under the moving train at a speed of $120 \mathrm{~km} / \mathrm{h}$, relative to the initial value (under self-weight). Cable responses induced by the moving train consisted mainly of in-plane vibrations (vertical and longitudinal direction),

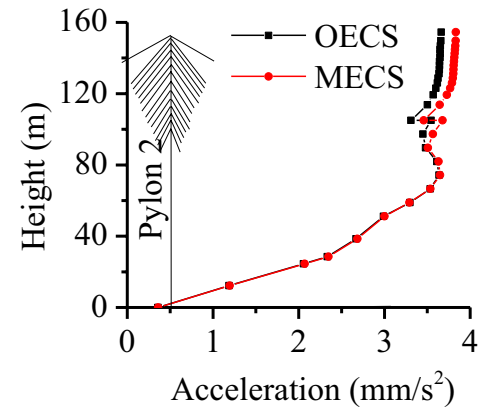

(a)

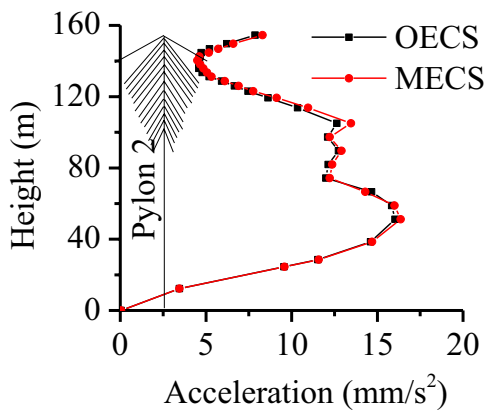

(b)

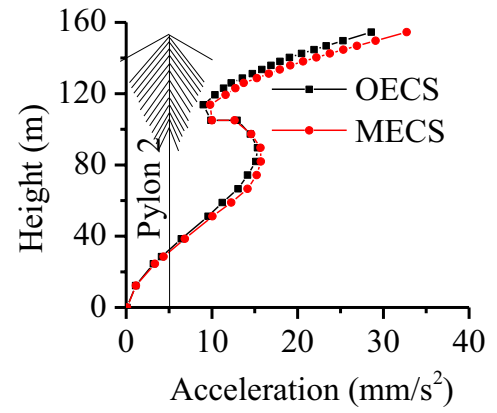

(c)

Fig. 7 Computed maximum acceleration of pylon 2: a vertical; $\mathbf{b}$ lateral; $\mathbf{c}$ longitudinal

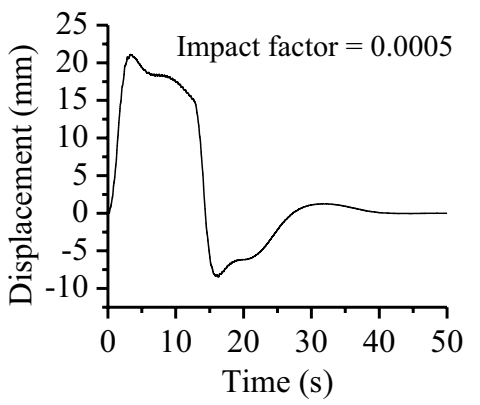

(a)

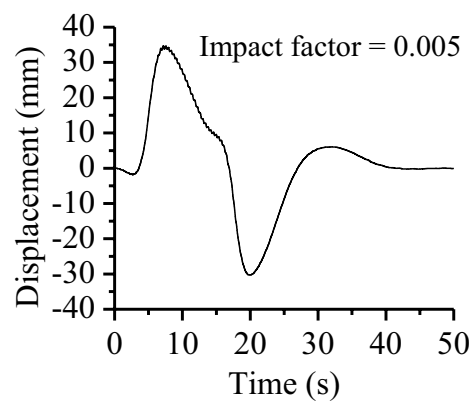

(b)

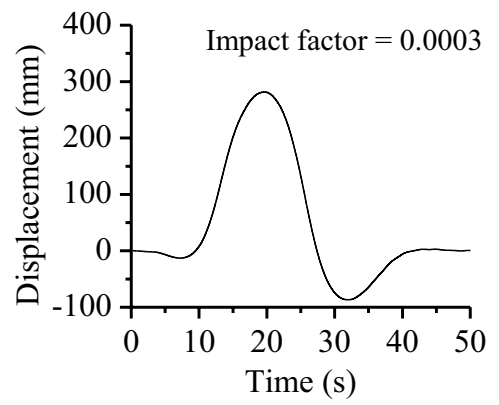

(c)

Fig. 8 Vertical displacement responses of the girder with the MECS model: a midpoint of span 1 with span=98 m; $\mathbf{b}$ midpoint of span 2 with span $=140 \mathrm{~m} ; \mathbf{c}$ midpoint of span 3 with $\operatorname{span}=406 \mathrm{~m}$

Fig. 9 Maximum responses of midpoint of cables relative to the initial value under a moving train $(V=120 \mathrm{~km} / \mathrm{h})$ : a displacement; $\mathbf{b}$ acceleration

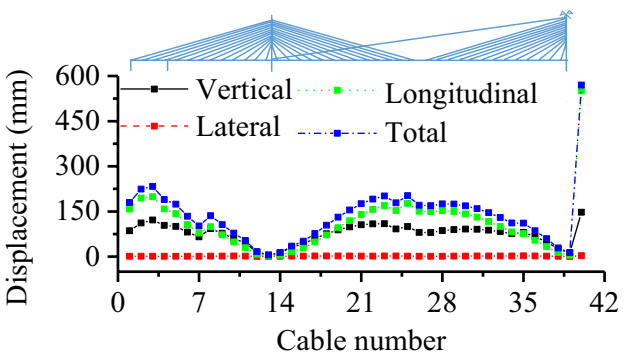

(a)

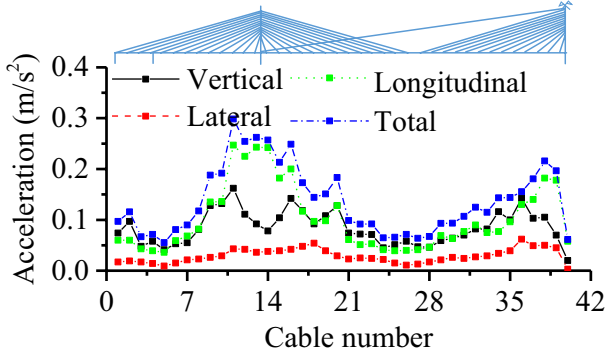

(b) 
whereas out-of-plane vibrations (lateral direction) were insignificant. Additionally, maximum displacements tended to be positively correlated with cable length negatively correlated with maximum acceleration. In particular, the overall maximum displacement occurs in stabilizing cable C40 (with vertical and longitudinal components of $550.33 \mathrm{~mm}$ and $147.57 \mathrm{~mm}$, respectively). Note that these behaviors cannot be simulated by the OECS model.

When the train passed the cable support in the main girder, the evenly spaced train axle load induced periodic excitation in the cables. If the natural frequency of the cables aligns with the excitation frequency of the train axle load, then cable resonance could occur. For wagon C80, the train axle load interval was $13 \mathrm{~m}$ and the excitation frequency was $2.56 \mathrm{~Hz}$. This excitation frequency was closer to twice the 1st frequency $(1.29 \mathrm{~Hz})$ of cables $\mathrm{C} 11$ to $\mathrm{C} 14$. Maximum accelerations of these cables were of larger magnitude than those of the other cables (recall Fig. 9b).

Figure 10 shows the displacement time histories of the cable midpoints and endpoints in the MECS model. Each nodal displacement can be separated into vertical, lateral, and longitudinal components. The suffixes "-G" and "-T" refer to the endpoint in the main girder and tower, respectively. The dynamic response of a short cable was less than that of the endpoints at the main girder and tower. For stabilizing cable $\mathrm{C} 40$, displacements were mainly induced by longitudinal vibrations in the pylon. Note, again, that such behaviors cannot be captured by the OECS model.

\section{Tension of cables}

Cable stress amplitudes obtained from the OECS and MECS models during train passage are shown in Fig. 11. The percentage differences of the stress amplitudes of most short cables were within 5\%. The largest difference of the stress amplitudes was found in the stabilizing cable, reaching $16 \%$. These comparisons indicate that although the OECS and MECS models can be used rationally to model the stresses in

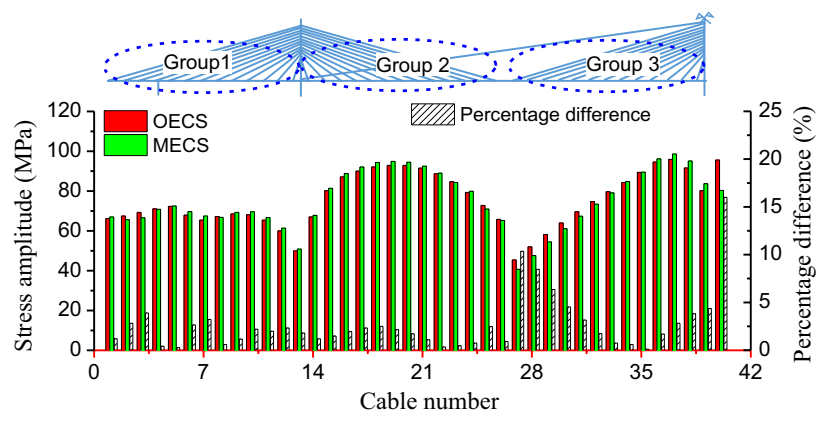

Fig. 11 Comparison of maximum dynamic cable stress amplitudes
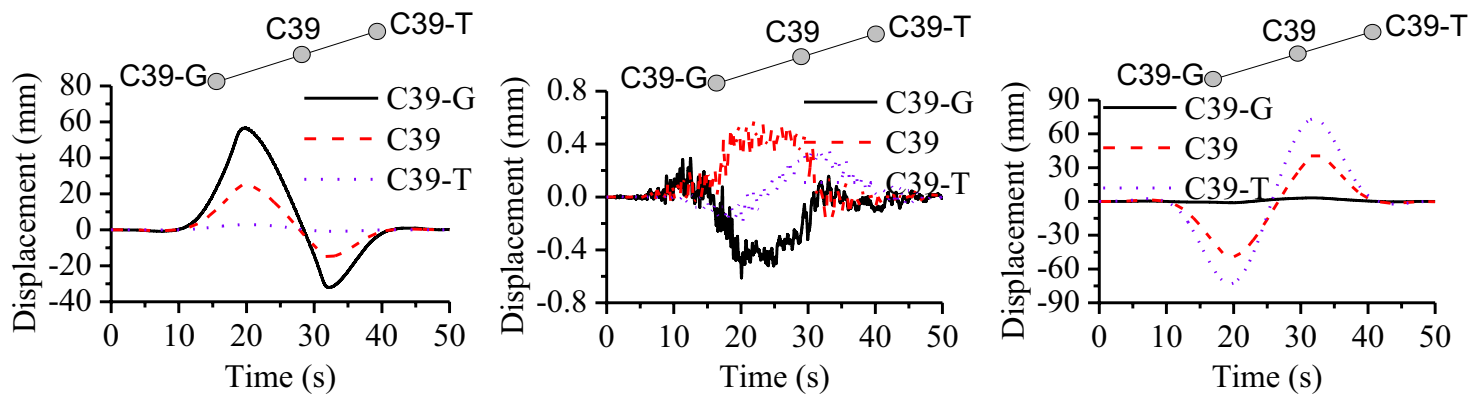

(a)
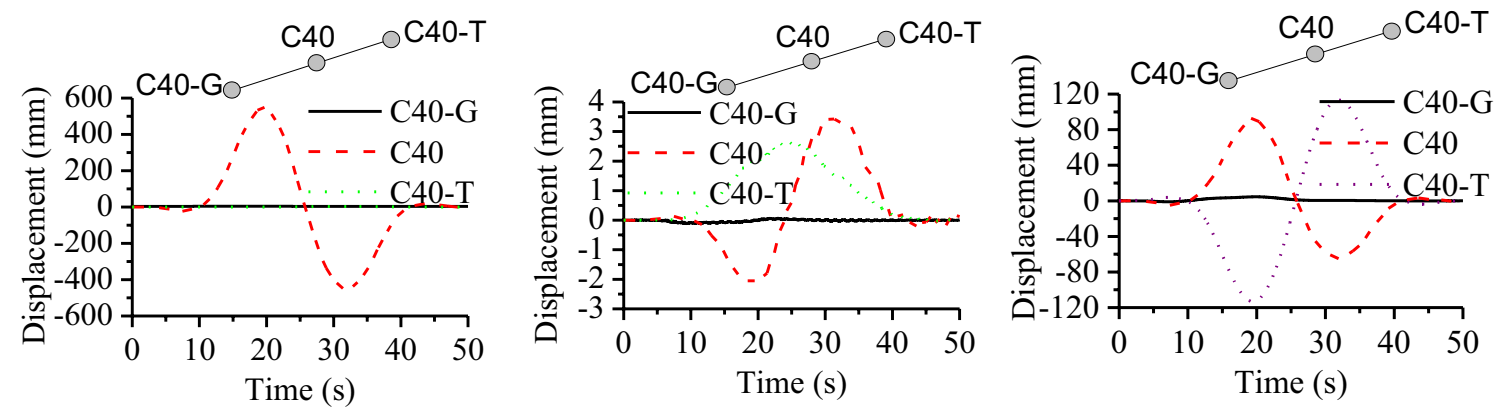

(b)

Fig. 10 Vertical, lateral, and longitudinal displacement time histories of cable midpoints and endpoints: a cable 39; b cable 40 
Fig. 12 Cable stresses during train passages at $120 \mathrm{~km} / \mathrm{h}: \mathbf{a}$ one element cable system; $\mathbf{b}$ multi-element cable system

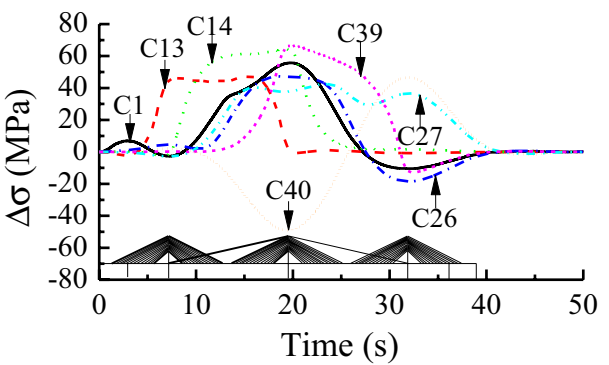

(a)

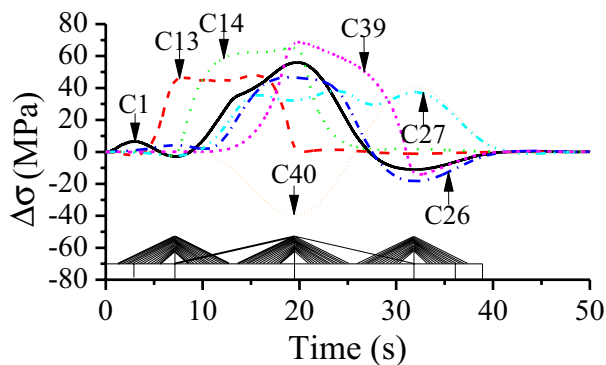

(b) relatively shorter cables, the MECS model was more suitable for analysis of stresses in relatively longer cables. Shown in Fig. 12 are train-induced stress time histories of selected cables (OECS vs. MECS). Time variations in cable tension are similar across both model types, where stress levels were significantly influenced by train location. Controlling stresses developed in cables C13, C14, and C39 for much of the train passage. However, during train passage across span 3, stresses in cable $\mathrm{C} 1$ increased significantly, while the stabilizing cable $\mathrm{C} 40$ underwent significant reductions in stress. In contrast, cable C27 maintained elevated stress levels as the train passed across span 3.

\section{Conclusions}

This study proposed a computational framework to analyze nonlinear dynamic responses of long-span cable-stayed bridges subjected to moving train loads, on the basis of a train-bridge coupled system. Two approaches for modeling cable stays were investigated: one element cable system (OECS) and multi-element cable system (MECS). The proposed framework and modeling approaches were applied in a case study of the Dongting Lake Railway Cable-Stayed Bridge (DRCB) to compute local cable vibrations and global vibrations under train passages and thereby illustrate important differences between the OECS and MECS approaches.

Based on the case study and train passage scenarios considered, the MECS approach is recommended for use in assessing the influence of cable vibration on nonlinear train-induced (dynamic) responses of long-span cable-stayed bridges. Nevertheless, influences of different train speeds and track irregularities need to be examined further when investigating the dynamic responses of bridge details, such as resonance speed and impact factor of orthotropic steel bridge decks.

Characteristics of computed vibrations of the DRCB bridge models are summarized as follows:

1. Compared to the OECS model, the MECS model can better capture local cable vibrations and the influence of these vibrations on nonlinear dynamic response of the cable-stayed bridge in the train-bridge coupled system. This can lead to a more reliable estimation of the dynamic cable responses.

2. Results of the modal analysis indicated that OECS model is capable of capturing global bridge motions, but unable to capture the mode shapes of individual stay cables. Further, the OECS model does not account for interactions between the stay cables and the deck-tower system. On the other hand, the MECS model effectively simulated the local and coupled motions.

3. Nonlinear dynamic analysis results indicated that although the OECS model can rationally model the deformations and internal forces of the deck-tower system and the internal forces of stay cables, it cannot simulate stay cable vibrations. On the other hand, the MECS model can capture both structural motions and internal forces of all bridge components, particularly those of the stay cables.

4. The dynamic responses of a long-span, cable-stayed bridge induced by a moving train are mainly in-plane vibrations (vertical and longitudinal direction). Outof-plane vibration (lateral direction) responses were insignificant during train passages on the DRCB model. Both the OCES and MECS approaches indicated that the DRCB satisfies code-prescribed limits for train-induced vibrations.

Acknowledgements The authors are grateful to the financial support provided by the National Natural Science Foundation of China (Nos. 51378021 and 11572117) and Hunan Province University Innovation Platform Open Foundation Project (13K006).

Open Access This article is distributed under the terms of the Creative Commons Attribution 4.0 International License (http://creativeco mmons.org/licenses/by/4.0/), which permits unrestricted use, distribution, and reproduction in any medium, provided you give appropriate credit to the original author(s) and the source, provide a link to the Creative Commons license, and indicate if changes were made. 


\section{References}

Abdel-Ghaffar AM, Khalifa MA (1991) Importance of cable vibration in dynamics of cable-stayed bridges. J Eng Mech 117(11):2571-2589

ANSYS 14.0 (2014) Computer software. ANSYS, Canonsburg

Asgari B, Osman SA, Adnan A (2013) Three-dimensional finite element modelling of long-span cable-stayed bridges. IES J Part A Civ Struct Eng 6(4):258-269

Au FTK, Cheng YS, Cheung YK, Zheng DY (2001a) On the determination of natural frequencies and mode shapes of cable-stayed bridges. Appl Math Model 25(12):1099-1115

Au FTK, Wang JJ, Cheung YK (2001b) Impact study of cable-stayed bridge under railway traffic using various models. J Sound Vib 240(3):447-465

Broughton P, Ndumbaro P (1995) The analysis of cable and catenary structures. Thomas Telford Publishing, London

Bruno D (2008) Dynamic impact analysis of long span cable-stayed bridges under moving loads. Eng Struct 30(4):1160-1177

Caetano E, Cunha A, Taylor C (1996) Experimental analysis of coupled cable-deck motions in cable-stayed bridges. In: 11th World conference on earthquake engineering, p 913

Caetano E, Cunha A, Gattulli V, Lepidi M (2008) Cable-deck dynamic interactions at the international guadiana bridge: on-site measurements and finite element modelling. Struct Control Health Monit 15(3):237-264

Cai H, Aref AJ (2014) Three-dimensional geometric nonlinear analysis of composite cable-stayed bridges using a refined double-beam model. J Bridge Eng 19(6):213-226

Chen G, Zhai WM (2004) A new wheel/rail spatially dynamic coupling model and its verification. Veh Syst Dyn 41(4):301-322

CMR (China Ministry of Railways) (2005) Fundamental code for design of railway bridges and culverts. TB 10002.1-2005. China Railway Publishing House, Beijing

Ernst JH (1965) Der E-modul von seilen under berücksichtigung des durchhanges. Bauing 40(2):52-55

Guo WW, Xia H, De Roeck G, Liu K (2012) Integral model for traintrack-bridge interaction on the Sesia viaduct: dynamic simulation and critical assessment. Comput Struct 112-113:205-216

Jesus AH, Dimitrovová Z, Silva MAG (2014) A statistical analysis of the dynamic response of a viaduct. Eng Struct 71(15):1-10

Jie W, Dan MF, Soliman M (2015) Geometry control simulation for long-span steel cable-stayed bridges based on geometrically nonlinear analysis. Eng Struct 90:71-82

Li H, Xia H, Soliman M, Frangopol DM (2015a) Bridge stress calculation based on the dynamic response of coupled train-bridge system. Eng Struct 99:334-345
Li Y, Dong S, Bao Y, Chen K, Qiang S (2015b) Impact coefficient analysis of long-span railway cable-stayed bridge based on coupled vehicle-bridge vibration. Shock Vib 2015:1-9

Stolarski T, Nakasone Y, Yoshimoto S (2007) Engineering analysis with ANSYS software. Butterworth-Heinemann, Oxford

Wang PH, Tseng TC, Yang CG (1993) Initial shape of cable-stayed bridges. Comput Struct 47(1):111-123

Warnitchai P, Fujino Y, Susumpow T (1995) Non-linear dynamic model for cables and its application to a cable-structure system. J Sound Vib 187(4):695-712

Wu Q, Takahashi K, Chen B (2006) Using cable finite elements to analyze parametric vibrations of stay cables in cable-stayed bridges. Struct Eng Mech 23:691-711

Yau JD, Yang YB (2004) Vibration reduction for cable-stayed bridges traveled by high-speed trains. Finite Elem Anal Des 40(03):341-359

Zaman M, Taheri MR, Khanna A (1996) Dynamic response of cablestayed bridges to moving vehicles using the structural impedance method. Appl Math Model 20(12):877-889

Zárate BA, Caicedo JM (2015) Effects of cable dynamics in the modeling of cable-stayed bridges under seismic excitation. Int J Struct Stab Dyn 15(04):1450061

Zhai WM, Cai CB, Guo SZ (1996) Coupling model of vertical and lateral vehicle/track interactions. Veh Syst Dyn 26(1):61-79

Zhai W, Wang K, Cai C (2009) Fundamentals of vehicle-track coupled dynamics. Veh Syst Dyn Int J Veh Mech Mobil 47(11):1349-1376

Zhai W, Wang S, Zhang N, Gao M, Xia H, Cai C, Zhao C (2013) High-speed train-track-bridge dynamic interactions-part II: experimental validation and engineering application. Int J Rail Transp 1(1-2):25-41

Zhang N, Xia H, Guo W (2008) Vehicle-bridge interaction analysis under high-speed trains. J Sound Vib 309(3-5):407-425

Zhang W, Cai CS, Pan F (2013) Finite element modeling of bridges with equivalent orthotropic material method for multi-scale dynamic loads. Eng Struct 54:82-93

Zhu Z, Davidson MT, Harik IE, Yu Z (2017) Train-induced vibration characteristics of an integrated high-speed railway station. ASCE J Perform Constr Facil 31:4

Zhu Z, Gong W, Wang L, Li Q, Bai Y, Yu Z, Harik IE (2018) An efficient multi-time-step method for train-track bridge interaction. Comput Struct 196:36-48

Publisher's Note Springer Nature remains neutral with regard to jurisdictional claims in published maps and institutional affiliations. 